\title{
BMJ Open One-year rehospitalisations for congestive heart failure in Portuguese NHS hospitals: a multilevel approach on patterns of use and contributing factors
}

\author{
Bruno Moita, ${ }^{01,2}$ Ana Patricia Marques, ${ }^{3,4}$ Ana Maria Camacho, ${ }^{2}$ \\ Pedro Leão Neves, ${ }^{2,5}$ Rui Santana ${ }^{3,4}$
}

To cite: Moita B, Marques AP, Camacho AM, et al. One-year rehospitalisations for congestive heart failure in Portuguese NHS hospitals: a multilevel approach on patterns of use and contributing factors. BMJ Open 2019;9:e031346. doi:10.1136/ bmjopen-2019-031346

- Prepublication history and additional material for this paper are available online. To view these files, please visit the journal online (http://dx.doi. org/10.1136/bmjopen-2019031346).

Received 29 April 2019 Revised 09 July 2019 Accepted 06 August 2019

Check for updates

(C) Author(s) (or their employer(s)) 2019. Re-use permitted under CC BY-NC. No commercial re-use. See rights and permissions. Published by BMJ.

${ }^{1}$ Escola Nacional de Saúde Pública, Universidade Nova de Lisboa, Lisboa, Portugal ${ }^{2}$ Centro Hospitalar Universitário do Algarve, Faro, Portugal ${ }^{3}$ Departamento de Políticas e Gestão dos Sistemas de Saúde, Escola Nacional de Saúde Pública, Universidade Nova de Lisboa, Lisboa, Portugal ${ }^{4}$ Centro de Investigação em Saúde Pública, Universidade Nova de Lisboa, Lisboa, Portugal ${ }^{5}$ Departamento de Ciências Biomédicas e Medicina, Universidade do Algarve, Faro, Portugal

Correspondence to

Bruno Moita;

b.moita@ensp.unl.pt

\section{ABSTRACT}

Objectives Identification of rehospitalisations for heart failure and contributing factors flags health policy intervention opportunities designed to deliver care at a most effective and efficient level. Recognising that heart failure is a condition for which timely and appropriate outpatient care can potentially prevent the use of inpatient services, we aimed to determine to what extent comorbidities and material deprivation were predictive of 1 year heart failure specific rehospitalisation.

Setting All Portuguese mainland National Health Service (NHS) hospitals.

Participants A total of 68565 hospitalisations for heart failure principal cause of admission, from 2011 to 2015, associated to 45882 distinct patients aged 18 years old or over.

Outcome measures We defined 1 year specific heart failure rehospitalisation and time to rehospitalisation as outcome measures.

Results Heart failure principal diagnosis admissions accounted for $1.6 \%$ of total hospital NHS budget, and over $40 \%$ of this burden is associated to patients rehospitalised at least once in the 365-day follow-up period. $22.1 \%$ of the patients hospitalised for a principal diagnosis of heart failure were rehospitalised for the same cause at least once within 365 days after previous discharge. Nearly $55 \%$ of rehospitalised patients were readmitted within 3 months. Results suggest a mediation effect between material deprivation and the chance of 1 year rehospitalisation through the effect that material deprivation has on the prevalence of comorbidities. Heart failure combined with chronic kidney disease or chronic obstructive pulmonary disease increases by 2.8 and 2.2 times, respectively, the chance of the patient becoming a frequent user of inpatient services for heart failure principal cause of admission.

Conclusions One-fifth of patients admitted for heart failure are rehospitalised due to heart failure exacerbation. While the role of material deprivation remained unclear, comorbidities considered increased the chance of 1 year heart failure specific rehospitalisation, in particular, chronic kidney disease and chronic obstructive pulmonary disease.
Strengths and limitations of this study

- Study focus on heart failure, a condition presenting growing incidence and prevalence trends in ageing populations, with significant burden to society, yet, a condition for which timely and appropriate outpatient care can potentially prevent inpatient admissions.

- A unique analysis of patterns of use, comorbidity and material deprivation association with 1 year specific rehospitalisation for heart failure, adopting a multilevel approach, allowing repeated observations per patient, covering a 5 -year follow-up period and all admissions from an entire National Health Service public hospitals population.

- To authors' best knowledge, the first study for the Portuguese setting addressing specific comorbidity and socio-economic association with the risk of 1 year specific rehospitalisation for heart-failure.

- Study relied on administrative discharge data source, with International Classification of Diseases, Ninth Revision, Clinical Modification classification, as granular clinical parameters and serum markers results were not available.

- The assessment of socioeconomic status (SES) was made at municipality level, using Carstairs Index methodology, as no individual SES measures were available.

\section{INTRODUCTION}

Symptomatic heart failure affected 37.7 million patients worldwide in 2010 , led to 4.2 million years lived with disability ${ }^{1}$ and was the leading cause of hospitalisation for older adult population in Europe and in the USA. ${ }^{2}$ In Europe, the prevalence of symptomatic heart failure in general population is estimated to range from $0.4 \%$ to $2.0 \%{ }^{3}$ Recent projections show that, in the USA, more than 8 million inhabitants, aged 18 or over, are likely to be diagnosed with heart failure by 2030 , representing a $46 \%$ prevalence increase compared with $2014 .^{4}$ 
Heart failure (HF) is widely recognised as an ambulatory care sensitive condition (ACSC),${ }^{5-9}$ meaning that a timely and effective outpatient care can help reduce the risk of hospitalisation by either preventing the onset of an illness or condition, controlling an acute episodic illness or condition or managing a chronic disease or condition. ${ }^{10}$ However, potential preventability of heart failure related hospitalisations should be interpreted with caution since the disease is a chronic progressive disorder and its preventability is expected to decrease with the progression of the condition. ${ }^{11}$

Hospitalisations for HF are strongly associated to age, sex, to a set of clinical parameters and to the presence of other chronic conditions. Among these, ischaemic heart disease (IHD), hypertension, diabetes, chronic kidney disease (CKD), chronic obstructive pulmonary disease (COPD) and previous myocardial infarction are conditions frequently referenced. ${ }^{2} 312$ Patients' attitudes and preferences towards treatment and disease management, ${ }^{13-15}$ as well as socioeconomic status, are factors also associated with the incidence and prevalence of $\mathrm{HF}$, the outcomes of care and healthcare use. ${ }^{16-18}$

Systematic use of inpatient services, apart from flagging potential deficits of hospital previous effectiveness, lack of transitional-care strategies and quality of follow-up outpatient care, is associated with inefficient use of scarce resources and increased risk of adverse events. ${ }^{19-22}$

Several underlying measures have been used to capture systematic use of inpatient services. Depending on the focus of the analysis, either frequency, intensity of use or the combination of both are reported..$^{23-26}$ In that related to frequency of use, 30-day readmission rates are widely referenced. The assessment of longer time intervals between hospitalisations, addressing the concept of patients with multiple admissions ${ }^{13}{ }^{27-29}$ may reveal patterns not apparent within 30 days after previous discharge $^{30}$ and increase the probability that rehospitalisations captured are related to outpatient quality of care. ${ }^{31}$ Therefore it is apparently aligned with the premises of $\mathrm{HF}$ as ACSC.

The purpose of the present study was to describe frequent use of inpatient services for HF principal cause of admission, at national level in a universal and free healthcare service, and to determine to what extent comorbidities and material deprivation were predictive of 1 year $\mathrm{HF}$ specific rehospitalisations. To authors' present and best knowledge little evidence has been produced adopting a multilevel approach and scarce literature has been found for the Portuguese context.

\section{METHODS}

\section{Data sources and study population}

Inpatient discharge minimum data set containing data from all mainland Portuguese National Health Service (NHS) public hospitals $(\mathrm{n}=51)$ was used. Raw data set contained information on 4922330 inpatient discharges from 1 January 2011 until 31 December 2015 associated to 2574887 unique patients.

A unique patient identifier, irreversibly encrypted by data provider, was available and used to follow each patient throughout the period. For each inpatient entry, the data set contains information on patients' age, gender, place of residence and on discharge diagnosis (up to 75), procedures (up to 75), discharge status of the patient, institutional hospital provider, admission and discharge dates and length of stay. Diagnosis and procedures were coded according to International Classification of Diseases, Ninth Revision, Clinical Modification (ICD-9-CM).

\section{Data preparation and outcome measures}

A set of validation routines were applied to the raw data set. We excluded all observations with missing unique patient identifier, missing gender, missing municipality of residence or not living in mainland Portuguese municipalities, duplicate entries and entries with errors. The second step excluded observations with no HF principal diagnosis and observations associated to patients aged under 18 years old at date of admission.

Panel data, allowing repeated observation per patient in different years, with summary measures of all included hospitalisations was defined as our working database, containing a total of 51310 observations, associated to 45 882 distinct patients and 68565 hospitalisations.

HF was identified according to Agency for Healthcare Research and Quality (AHRQ) prevention quality indicator on heart failure admission rate. ${ }^{5}$

A binary variable indicating 1 year specific heart failure frequent use was defined as our primary outcome measure. This variable indicates whether a patient was associated to two or more admissions with a principal diagnosis of HF in a 365-day look-back period. Similarly, it can also be read as an indicator on whether the patient was rehospitalised at least once for HF specific cause in a 365-day period.

Identification of systematic use of inpatient services was made adapting Canadian Institute for Healthcare Information methodology ${ }^{2532}$ to exclusively capture frequency of use. Index admission was defined as the most recent admission in each civil year, and the assessed year and 365-day look-back period were defined based on index admission date. This approach requires data from three civil years to assess frequent use over a 365-day look-back period. Consequently, initial data from 2011 until 2015 allowed us to assess frequent use in 2012, 2013 and 2014.

Ischaemic heart disease, diabetes, hypertension, chronic obstructive pulmonary disease, previous myocardial infarction and chronic kidney disease were identified as comorbidities, based on literature review, ${ }^{33-36}$ from the set of diagnosis present in each discharge (see online supplementary data 1). The enhanced ICD-9-CM version of Charlson Comorbidity Index was computed as defined by Quan $e t$ al to assess aggregate differences in severity of comorbidities other than HF. ${ }^{37}$ 
To assess small-area, municipality-level material deprivation Carstairs Index was computed based on methodological notes by Brown et al, ${ }^{38}$ with adaptations related to data availability. A 2011 Portuguese census data ${ }^{39}$ on male unemployment, overcrowded households, population not using individual transport in commuting and households with low social class active head were normalised and summed to construct the composite index (see online supplementary data 2). The index was stratified in population-weighted quintiles, in ascending order of material deprivation, each municipality classified accordingly, and matched to each patient municipality of residence.

\section{Statistical analysis}

Baseline characteristics are presented as percentages or mean. Distributional tests were performed and differences in baseline characteristics were tested using chi-squared, Mann-Whitney and proportion z-tests.

To assess municipality-level geographical variation, population-weighted age standardised yearly heart failure use rate and frequent use rate per 10000 inhabitants, aged 20 years or older, were computed considering the number of patients verifying use or frequent use in each year. Direct standardisation approach was used assuming 2013 European standard population. ${ }^{40}$
To predict 1 year specific HF frequent use chance, logistic regression analysis assuming hierarchical multilevel modelling with random effects was adopted. Our baseline assumed a three-level random-intercept logistic regression model with year observations $i$ nested in patients $j$ in turn nested in municipalities $k$. As we allowed repeated observations per patient in different years, the lowest level of aggregation was specific patient year data. The underlying motivation for multilevel modelling resides in the fact that higher-level factors might influence lower-level outcomes ${ }^{41}{ }^{42}$ and consequently, coefficients are corrected for attenuation due to unobserved heterogeneity at different levels. ${ }^{43}$ Preliminary analysis of residual intraclass correlation have shown no association between latent measurements of frequent use $(\approx 1 \%)$ in the same municipality. This suggest that dropping municipality level would produce similar estimates and, consequently, a parsimonious approach was adopted and analysis was conducted with two levels (see online supplementary data 3 ).

As estimations were made over a sample of users of inpatient services for $\mathrm{HF}$, each coefficient must be interpreted as the increased chance of becoming frequent user among patients that already use inpatient services

Table 1 Sociodemographic and morbidity characteristics of heart failure patients with inpatient admissions in NHS Portuguese public hospitals from 2012 to 2014

\begin{tabular}{|c|c|c|c|c|c|c|}
\hline & \multirow{2}{*}{\multicolumn{2}{|c|}{$\begin{array}{l}\text { Occasional users }^{*} \\
\mathrm{n}=39994 \text { patients }\end{array}$}} & \multirow{2}{*}{\multicolumn{2}{|c|}{$\begin{array}{l}\text { Frequent users } \dagger \\
\mathrm{n}=11316 \text { patients }\end{array}$}} & \multirow{2}{*}{\multicolumn{2}{|c|}{$\begin{array}{l}\text { Tests on mean or proportions } \\
\text { differences }\end{array}$}} \\
\hline & & & & & & \\
\hline & Mean or $\%$ & SD & Mean or $\%$ & SD & Test & $P$ value \\
\hline Female (\%) & 56.5 & & 55.8 & & Proportions z-test & 0.1847 \\
\hline \multicolumn{7}{|l|}{ Discharge status (\%) } \\
\hline Death & 14.5 & & 19.0 & & & \\
\hline $\begin{array}{l}\text { Charlson comorbidity index (ungrouped } \\
\text { score) }\end{array}$ & 2.7 & 1.6 & 3.0 & 1.5 & Mann-Whitney & $<0.001$ \\
\hline Ischaemic heart disease (\%) & 22.6 & & 37.4 & & Proportions z-test & $<0.001$ \\
\hline Diabetes (\%) & 35.0 & & 46.5 & & Proportions z-test & $<0.001$ \\
\hline Chronic kidney disease (\%) & 25.0 & & 46.5 & & Proportions z-test & $<0.001$ \\
\hline Material deprived municipality (\%) & & & & & $\chi^{2}$ & $<0.001$ \\
\hline Quintile 1 - least deprived & 21.2 & & 19.2 & & & \\
\hline Quintile 2 & 20.4 & & 20.1 & & & \\
\hline Quintile 3 & 18.0 & & 16.2 & & & \\
\hline Quintile 4 & 22.6 & & 25.9 & & & \\
\hline Quintile 5 - most deprived & 17.8 & & 18.6 & & & \\
\hline
\end{tabular}

${ }^{*}$ One heart failure principal diagnosis admission within 365-day look-back period †Two or more heart failure principal diagnosis admissions within 365-day look-back period. COPD, chronic obstructive pulmonary disease; NHS, National Health Service. 
for HF. For instance, despite a given covariate might be associated with a higher chance of inpatient use for HF, it might not be significant to differentiate frequent from occasional users.

Sensitivity analysis was performed to test for the hypothesis of biassed results due to the inclusion of patients that died in any of the admissions included.

All statistical analyses were performed using Stata (StataCorp, Texas, USA) V.14.2 and assuming a 5\% level of significance.

\section{RESULTS}

From 2012 to 2014, 51310 patients with a principal diagnosis of heart failure were hospitalised in NHS Portuguese public hospitals. These patients had 68565 admissions corresponding to 665000 bed-days occupied and costing, in inpatient hospital services, up to EUR 193 million, around $1.6 \%$ of total Portuguese hospital NHS budget.

Baseline characteristics of the patients at first admission (see online supplementary data 4) show prevalence of females $(56.3 \%)$, advanced age of patients (78.4 years old) and an average ungrouped Charlson Comorbidity Score of 2.7. The most prevalent comorbidities associated to patients admitted for HF were hypertension (69.6\%), diabetes $(36.5 \%)$, CKD $(28.2 \%)$ and ischaemic heart disease $(24.7 \%)$.

We found that $22.1 \%(\mathrm{n}=11316)$ of the patients were classified as frequent users. These patients were rehospitalised for HF principal cause of admission at least once within 365 days after previous discharge for the same condition, accounted for $41.6 \%$ (EUR 80 million) of total HF inpatient costs in the period considered and represented an average annual cost of EUR 27 million.

Table 1 summarises sociodemographic and clinical characteristics of HF patients by inpatient type of use: occasional users and frequent users.

Except for gender, all covariates were associated with frequent use and differences found statistically significant.

Patients aged 65 years or older represented 89.6\% $(\mathrm{n}=45$ 980) of observations. Despite significant, arguably by sample size, age difference between occasional and frequent users is small. Frequent users are 0.1 years younger than occasional users.

Frequent users had higher Charlson Comorbidity Scores revealing increased severity of comorbidities other than $\mathrm{HF}$ and $19 \%$ died in hospital following an inpatient admission for HF principal diagnosis. Patients who died during an inpatient stay were significantly older $(82.6$ years vs 78.2 years), $55.8 \%$ were females and had a higher Charlson Comorbidity Score (2.96 vs 2.71). Prevalence of comorbidities was higher among rehospitalised patients and larger relative differences were found for previous myocardial infarction, ischaemic heart disease, chronic kidney disease and COPD.

Despite tenuous, compared with HF occasional users, HF frequent users present lower relative frequency in
Table 2 Association between municipality material deprivation index and Charlson comorbidity score among patients hospitalised for heart failure in Portuguese National Health Service hospitals, 2012 to 2014 ( $n=51310)$

\begin{tabular}{llll}
\hline \multirow{2}{*}{$\begin{array}{l}\text { Material } \\
\text { deprivation }\end{array}$} & $\begin{array}{l}\text { Average Charlson score } \\
\text { Occasional } \\
\text { users }^{*}\end{array}$ & $\begin{array}{l}\text { Frequent } \\
\text { users } \dagger\end{array}$ & Total \\
\hline $\begin{array}{l}\text { Quintile 1 - least } \\
\text { deprived }\end{array}$ & $2.43(1.45)$ & $2.71(1.29)$ & $2.49(1.42)$ \\
Quintile 2 & $2.62(1.59)$ & $2.88(1.40)$ & $2.68(1.56)$ \\
Quintile 3 & $2.64(1.57)$ & $2.94(1.48)$ & $2.70(1.56)$ \\
$\begin{array}{l}\text { Quintile 4 } \\
\text { Quintile 5 - most } \\
\text { deprived }\end{array}$ & $2.83(1.71)$ & $3.22(1.58)$ & $2.93(1.69)$ \\
\hline
\end{tabular}

*One heart failure principal diagnosis admission within 365-day look-back period.

†Two or more heart failure principal diagnosis admissions within 365-day look-back period; population-weighted quintiles; SD in parentheses.

less deprived municipalities and higher concentration on more deprived municipalities.

Table 2 shows that average Charlson Comorbidity Score increase with municipality material deprivation quintile. Moreover, also confirm the same trend stratifying results by type of inpatient use and show that, on average, patients rehospitalised within 1 year for HF have higher Charlson Comorbidity Scores than those who were not rehospitalised.

Table 3 summarises inpatient use characteristics by type of inpatient user.

On average, HF frequent users had 2.5 inpatient admissions $(\sigma=1.0)$ in a given year and $52 \%$ of these patients occupied an hospital bed for at least 20 days. HF specific rehospitalisation rate at 30 days was $4.9 \%$, at 90 days $12.1 \%$, at 180 days $17.8 \%$ and at 1 year $22.1 \%$.

Frequent users amounting to $68.2 \%$ were rehospitalised for HF once within 1 year after previous discharge for HF $(n=7715), 20.2 \%$ two times $(n=2292)$ and $11.6 \%$ were rehospitalised three or more times $(n=1309)$. Average time to rehospitalisation was 108 days $(\sigma=93.3)$ and $50 \%$ of rehospitalised patients were so within 78 days after previous discharge. Among 11316 rehospitalised patients, $21.8 \%$ were so within 30 days and $54.9 \%$ within 90 days after previous discharge.

Average HF age standardised inpatient services use rate, for 2012 to 2014 period, was 21.2 per 10000 adult inhabitants $(\sigma=5.08)$. Additionally, average HF age standardised inpatient services frequent use rate, for 2012 to 2014 period, was 4.67 per 10000 adult inhabitants $(\sigma=1.77)$. Differences in proportions of $\mathrm{HF}$ frequent users at municipality level were assessed with chi-squared test and the null hypothesis for equal proportions was rejected $(p<0.001)$ suggesting an association between municipality and frequent user variable. 
Table 3 Inpatient use characteristics of heart failure patients with inpatient admissions in NationalHealth Service Portuguese public hospitals from 2012 to 2014

\begin{tabular}{|c|c|c|c|c|c|c|}
\hline & \multirow{2}{*}{\multicolumn{2}{|c|}{$\begin{array}{l}\text { Occasional users }^{*} \\
\mathrm{n}=39994 \text { patients }\end{array}$}} & \multirow{2}{*}{\multicolumn{2}{|c|}{$\begin{array}{l}\text { Frequent users } t \\
n=11316 \text { patients }\end{array}$}} & \multirow{2}{*}{\multicolumn{2}{|c|}{$\begin{array}{l}\text { Tests on mean or proportions } \\
\text { differences }\end{array}$}} \\
\hline & & & & & & \\
\hline & Mean or $\%$ & SD & Mean or $\%$ & SD & Test & $P$ value \\
\hline Bed-days occupied (\%) & & & & & $\chi^{2}$ & $<0.001$ \\
\hline $0-2$ days & 12.9 & & 0.5 & & & \\
\hline 10-19 days & 26.5 & & 35.4 & & & \\
\hline 20-29 days & 5.9 & & 24.5 & & & \\
\hline 30-44 days & 2.3 & & 16.4 & & & \\
\hline$\geq 45$ days & 1.0 & & 11.1 & & & \\
\hline Average time to rehospitalisation (\%) & & & & & -- & -- \\
\hline 91-180 days & & & 25.7 & & & \\
\hline 180-365 days & & & 19.4 & & & \\
\hline
\end{tabular}

${ }^{*}$ One heart failure principal diagnosis admission within 365-day look-back period.

†Two or more heart failure principal diagnosis admissions within 365-day look-back period.

Bivariate analyses presented, despite relevant, fall short to estimate the association with the probability of becoming a frequent user for $\mathrm{HF}$ once other covariates are not controlled for. Even geographical rates were computed only controlling for age and omitting the fact that other covariates might play a significant role on explaining differences, as suggested by the results presented.

Table 4 summarises the logistic regression results for 1 year heart failure specific rehospitalisation assuming a two-level structure.

The first model considers material deprivation as the unique individual fixed effect and assumes patient level random effects. The second model adds to the first variables that does not vary with socioeconomic variations, that is, age and gender. The third one is the full model, which adds comorbidity covariates.

Model 1 material deprivation ORs show that, not taking into account other covariates, patients hospitalised for $\mathrm{HF}$ living in more deprived municipalities (quintiles 4 and 5) are more likely to become frequent users for HF than those who live in least deprived municipalities. In particular, those who had been hospitalised for heart failure and live in quintile 4 and quintile 5 material deprived municipalities are 1.29 and 1.17 times more likely to be rehospitalised for $\mathrm{HF}$ than those who live in quintile 1 material deprived municipalities. These estimates do not vary significantly after adjusting for age and sex (Model 2). However, material deprivation estimates are significantly reduced after comorbidity adjustment suggesting that material deprivation is indirectly associated with 1 year HF rehospitalisation through association it may have on the prevalence of comorbidities.

All comorbidities considered increase the chance of 1 year rehospitalisation and, in particular, chronic kidney disease and COPD have ORs of 2.8 and 2.2, respectively. Females are 1.15 times more likely to become HF frequent users than males; besides, age does not increase the chance of a HF inpatient user becoming frequent user when the prevalence of comorbidities is controlled for.

Sensitivity analysis was performed excluding patients with death discharge status. Results did not differ significantly from our baseline analysis and the hypothesis of biaised estimates due to inclusion of patients who died was not confirmed (see online supplementary data 5).

\section{DISCUSSION}

Heart failure admissions account for roughly $1.6 \%$ of total annual Portuguese hospital NHS budget, representing over EUR 65 million direct inpatient costs. Over $40 \%$ of this financial burden is attributable to patients that are admitted more than once for HF in a 365-day look-back period.

From 51310 patients admitted due to HF, 22.1\% where frequent users. HF frequent users had, on average, 2.5 inpatient admissions per year, $21.8 \%$ were rehospitalised within 30 days while $54.9 \%$ were rehospitalised within 90 days after previous discharge. Compared with patients with a single admission for $\mathrm{HF}$, females and patients with CKD, COPD, hypertension, diabetes or IHD were more likely to become HF frequent users. Age was not associated 
Table 4 Two-level logistic regression results for the latent probability of becoming heart failure inpatient frequent user $(n=51$ 310)

$\begin{array}{lll}\text { Model 1 } & \text { Model 2 } & \text { Model 3 } \\ \text { OR } & \text { OR } & \text { OR }\end{array}$

\section{Fixed-effects parameters}

Gender

Female

$0.968(0.0266)$

$1.151^{\star \star \star}(0.0287)$

Age

$(75 ; 84)$

$1.285^{\star \star \star}(0.0512)$

$1.031(0.0542)$

$(85+)$

$1.256^{\star \star \star}(0.0463)$

$1.010(0.0490)$

$1.075(0.0483)$

$0.917(0.0514)$

Diabetes

$1.345^{\star \star \star}(0.0289)$

Hypertension

COPD

Ischaemic heart disease

Previous myocardial infarction

Chronic kidney disease

Material deprivation

Quintile 2

$1.085^{*}(0.0409)$

$1.084^{*}(0.0408)$

$1.904^{\star * \star}(0.0343)$

$2.181^{\star \star \star}(0.0348)$

Quintile 3

$0.991(0.0428)$

$0.988(0.0428)$

$1.803^{\star \star \star}(0.0358)$

$1.537^{\star \star *}(0.0509)$

$2.804^{\star * *}(0.0317)$

Quintile 4

$1.299^{\star \star \star}(0.0391)$

$1.303^{\star \star \star}(0.0391)$

$0.974(0.0431)$

Quintile 5

$1.169^{\star \star \star}(0.0419)$

$1.173^{\star \star \star}(0.0419)$

$0.844^{\star * \star}(0.0453)$

0.968 (0.0418)

Constant

$0.180^{\star \star \star}(0.0371)$

$0.156^{\star \star \star}(0.0562)$

$0.833^{\star \star \star}(0.0451)$

$0.0526^{\star \star *}(0.0725)$

\section{Random-effects parameters}

Patient

SD (constant)

$1.086^{\star}(0.0377)$

$354.73^{\star \star \star}$

53723.3

$0.2639(0.0146)$

0.5255
$1.079 *(0.0380)$

$346.61^{\star \star *}$

$1.135^{\star \star}(0.0411)$

53679.4

$306.79^{\star * \star}$

49981.0

Residual intraclass correlation

Patient

$0.2614(0.0147)$

$0.2814(0.0166)$

C-statistic (AUC)

Without random-effects

Note: Standard errors in parentheses; ${ }^{*} p<0.05$, ${ }^{*} \mathrm{p}<0.01,{ }^{* * *} \mathrm{p}<0.001$.

AUC, area under the curve; COPD, chronic obstructive pulmonary disease; LR, logistic regression.

with rehospitalisation increased probability. Our results also suggest a potential mediation effect between smallarea material deprivation and the chance of 1 year rehospitalisation through the effect that material deprivation has on the prevalence of comorbidities.

We found that $22.1 \%$ of the patients $(n=11316)$ were rehospitalised for HF principal diagnosis at least once within 365 days after previous discharge. Similar 1 year specific HF rehospitalisation rates were found by Philbin for USA (21.3\%), although lower than those found by Robertson et al (32\%) and Al-Omary et al (27\%) for Australia. ${ }^{44-46}$ Other than potential differences on the prevalence and incidence of the disease and provider practices, both Australian studies present methodological options which can, in part, explain the higher rehospitalisation rate found. One year HF specific rehospitalisation rates are significantly lower comparing to all-cause rehospitalisation rates among patients with $\mathrm{HF}$ and literature reports, for the latter, values consistently over $50 \%$ and up to $73 \%{ }^{45-47}$

Among patients hospitalised for HF, age was not associated to an increased chance of rehospitalisation for the same cause within 1 year after previous discharge. Philbin heart failure readmission risk model did not retained age as a predictor while Robertson $e t a l$, using different age stratification, found statistical significant increased ORs, despite small, only for patients aged 75 years or older.

We found that the presence of other comorbidities play a significant role on the probability of 1 year specific HF rehospitalisation. Frequent users present, on average, higher severity of illness and higher likelihood of 1 year post-discharge death, measured by Charlson Comorbidity 
Score. HF patients with hypertension, COPD or chronic kidney disease are between 2.8 and 1.9 times more likely to be rehospitalised for HF exacerbation than patients with no comorbidities other than HF. Risk score model developed by Philbin retained renal disease, IHD and respiratory tract chronic diseases as predictors of higher risk of HF specific readmission. European Society of Cardiology HF guidelines also recognise the great importance of comorbidities, not only as contributors to the burden of hospitalisations, but also as constraints to the use of treatment technologies. ${ }^{33}$

Material deprivation association with the probability of the patient to become recurrent inpatient user for HF remained unclear. Living in material deprived municipalities was associated to increased Charlson Comorbidity Scores and higher chance of 1 year HF specific rehospitalisation. However, after adjusting for comorbidities significant lowered probability of rehospitalisation had been found for patients living in Carstairs Index quintile 3 and 5 municipalities. Witte $e t a l^{18}$ found no significant association between small area material deprivation and 1 year HF specific readmission. Nevertheless, these authors found evidence for all-cause readmission for HF patients and for total number of bed-days occupied. Eapen et $a l^{17}$ found that county level socioeconomic status data is modestly associated with 30-day heart failure outcomes but do not improve risk adjustment models based on patients characteristics. With results obtained from present study we hypothesise an indirect association between material deprivation and the probability of 1 year specific rehospitalisation for heart failure through the association that material deprivation may have on the prevalence of comorbidities. ${ }^{48}$ However, either Akaike information criterion and c-statistic variation between models is small, revealing that directed future mediation analysis should be designed to evaluate the hypothesised mediation effect.

\section{Strengths, limitations and implications}

Our study has strengths and limitations. Once it relied exclusively on administrative discharge data sources, no specific inpatient care characteristics other than minimum discharge data set predefined variables were available, as well as information on outpatient care follow-up or granular clinical parameters. Among clinical parameters, evidence of association with all cause rehospitalisation rate has been found for left ventricular ejection fraction (LVEF), New York Heart Association Functional Classification (NYHA) and serum markers. In particular, unavailability of data regarding LVEF hinders the distinction of patients with preserved ejection fraction from those with reduced ejection fraction. Despite frequent inclusion of LVEF and NYHA in analyses as HF severity indicators, no consistent significant statistical association with readmission after hospitalisation for HF has been reported. ${ }^{349}$

Despite these limitations, notwithstanding that the availability of complementary information, including granular clinical parameters, would favour the external validity of results obtained and provide valuable insights on contributing factors for HF rehospitalisations, our model discriminatory and predictive ability, being modest (c-statistic $=0.68)$, is aligned with comparable studies. ${ }^{34}$ The completeness and validity ${ }^{50}$ of administrative national database covering all NHS hospital admissions in Portugal mainland and, consequently, distinct provider differentiation levels, clinical practices and patient characteristics, as well as the hierarchical regression modelling allowing to control for patient level unobserved heterogeneity, is a strength favouring generalisation of our findings.

Geographical aggregation of data was made at municipality level and multilevel modelling suggested no systematic geographical frequent use risk variation. Although our methodological options are supported either by demographic data availability or by a rationale justification, we acknowledge that data aggregation at different levels and different cut-offs might have produced different results.

Nearly $21.8 \%$ of patients $(\mathrm{n}=2466)$ were rehospitalised, on average, within 30 days and $54.9 \% \quad(n=6207)$ within 90 days after previous discharge. This result is suggestive of potential opportunities for ambulatory care follow-up, disease management programmes and transitional care strategies, as a significant proportion of rehospitalisations fall outside the traditional 30-day time frame for index admission quality of care assessment. However, advanced age and multimorbidity associated to patients with HF raise the discussion on potential preventability of admissions associated to these patients. The inclusion of information related to outpatient follow-up may provide a valuable insight on potential preventability of inpatient hospitalisations and subsequent readmissions associated to patient with HF. While some authors report that siloed and fragmented care hinders the goal of reducing HF admissions and subsequent rehospitalisations ${ }^{14} 51$ others suggest that early follow-up after discharge, multidisciplinary disease management, promotion of patient selfcare literacy and same-day access clinics for outpatient intravenous diuresis are effective in reducing admissions for $\mathrm{HF}^{33}{ }^{52-55}$

Multiple hospitalisations for patients with HF are common but less than one half are due to cardiovascular causes and only roughly $30 \%$ of rehospitalisations are for a HF specific cause. ${ }^{456}$ Our study focused, exclusively, on the latter. Hence, the positive externalities of successful health policy interventions and disease programme management might be highly leveraged by the potential impacts on preventing hospitalisations in patients with HF but due to other causes than HF.

\section{CONCLUSION}

Heart failure hospitalisations represent a significant burden for health systems with growing trends in developed countries. Assessing patterns of 1 year rehospitalisations due to heart failure exacerbation allowed us to describe, for the first time for the Portuguese context and at national level, the extent of the phenomena and 
provided useful insights on contributive factors. The presence of comorbidities was associated with an increased probability of 1 year rehospitalisation for heart failure exacerbation, confirming for this context previous reported associations. Our findings also suggest that the effect of living in material deprived municipalities was indirectly associated with the probability of rehospitalisation by the effect material deprivation has on the prevalence of comorbidities. Thus, successfully managing heart failure in outpatient setting, and consequently potentially preventing rehospitalisations, requires integrative and multidisciplinary approaches on care continuum.

Acknowledgements Authors would like to acknowledge Central Administration of the Health System, the public institute that ensures the management of human and financial resources of the Portuguese Ministry of Health, for providing access to inpatient discharge minimum data set.

Contributors BM conceived and designed the study, collected and analysed the data and drafted the manuscript. AMC and PLN advised on the analysis and presentation of results, on the discussion and provided clinical critical feedback. APM and RS participated in the design of the study, advised on the analysis and presentation of results, on the discussion and provided critical feedback to the manuscript. All the authors revised the manuscript for important intellectual content, contributed to the data interpretation and writing and critically reviewing of the manuscript at all stages and approved the final copy.

Funding The authors have not declared a specific grant for this research from any funding agency in the public, commercial or not-for-profit sectors.

Competing interests None declared.

Patient consent for publication Not required.

Ethics approval Authorisation to use data was obtained from Institutional Review Board (IRB) from Escola Nacional de Saúde Pública, Universidade NOVA de Lisboa. Data was made available anonymised by data provider and no patient is identifiable.

Provenance and peer review Not commissioned; externally peer reviewed.

Data availability statement Data may be obtained from a third party and are not publicly available.

Open access This is an open access article distributed in accordance with the Creative Commons Attribution Non Commercial (CC BY-NC 4.0) license, which permits others to distribute, remix, adapt, build upon this work non-commercially, and license their derivative works on different terms, provided the original work is properly cited, appropriate credit is given, any changes made indicated, and the use is non-commercial. See: http://creativecommons.org/licenses/by-nc/4.0/.

\section{REFERENCES}

1. Vos T, Flaxman AD, Naghavi M, et al. Years lived with disability (YLDs) for 1160 sequelae of 289 diseases and injuries 1990-2010: a systematic analysis for the global burden of disease study 2010 . Lancet 2012;380:2163-96.

2. Ambrosy AP, Fonarow GC, Butler J, et al. The global health and economic burden of hospitalizations for heart failure: lessons learned from hospitalized heart failure registries. J Am Coll Cardiol 2014;63:1123-33.

3. Nieminen MS, Brutsaert D, Dickstein K, et al. EuroHeart failure survey II (EHFS II): a survey on hospitalized acute heart failure patients: description of population. Eur Heart J 2006;27:2725-36.

4. Benjamin EJ, Virani SS, Callaway CW, et al. Heart disease and stroke Statistics-2018 update: a report from the American heart association. Circulation 2018;137:e67-492.

5. AHRQ. Inpatient Quality Indicators: Technical Specifications - Version 5.0, 2015. Available: http://www.qualityindicators.ahrq.gov/Archive/ IQI_TechSpec_ICD9_v50.aspx [Accessed 21 Aug 2018].

6. Canadian Institute for Health Information. Health indicators 2013: definitions, data sources and rationale. 22, 2013. Available: http:// www.cihi.ca/CIHI-ext-portal/pdf/internet/IND_DEFIN_2013_EN

7. Caminal Homar J, Morales Espinoza M, Sánchez Ruiz E, et al. [Hospitalizations preventable by timely and effective primary health care]. Aten Primaria 2003;31:6-17.
8. Purdy S, Griffin T, Salisbury C, et al. Ambulatory care sensitive conditions: terminology and disease coding need to be more specific to aid policy makers and clinicians. Public Health 2009;123:169-73.

9. Braunstein JB, Anderson GF, Gerstenblith G, et al. Noncardiac comorbidity increases preventable hospitalizations and mortality among Medicare beneficiaries with chronic heart failure. J Am Coll Cardiol 2003;42:1226-33.

10. Billings J, Zeitel L, Lukomnik J, et al. Impact of socioeconomic status on hospital use in New York City. Health Aff 1993;12:162-73.

11. Davies SM, Geppert J, McClellan M. Refinement of the HCUP Quality Indicators, Technical Reviews 4.0. Natl Cent Biotechnol Inf US Natl Libr Med, 2001. Available: https://www.ncbi.nlm.nih.gov/books/ NBK43831/ [Accessed 27 Aug 2018].

12. Fonarow GC, Abraham WT, Albert NM, et al. Age- and genderrelated differences in quality of care and outcomes of patients hospitalized with heart failure (from OPTIMIZE-HF). Am J Cardiol 2009;104:107-15.

13. Evangelista LS, Doering LV, Dracup K. Usefulness of a history of tobacco and alcohol use in predicting multiple heart failure readmissions among Veterans. Am J Cardiol 2000;86:1339-42.

14. Desai AS, Stevenson LW. Rehospitalization for heart failure: predict or prevent? Circulation 2012;126:501-6.

15. Chamberlain RS, Sond J, Mahendraraj K, et al. Determining 30-day readmission risk for heart failure patients: the readmission after heart failure scale. Int J Gen Med 2018;11:127-41.

16. Hawkins NM, Jhund PS, McMurray JJV, et al. Heart failure and socioeconomic status: accumulating evidence of inequality. Eur $J$ Heart Fail 2012;14:138-46.

17. Eapen ZJ, McCoy LA, Fonarow GC, et al. Utility of socioeconomic status in predicting 30-day outcomes after heart failure hospitalization. Circulation 2015;8:473-80.

18. Witte KK, Patel PA, Walker AMN, et al. Socioeconomic deprivation and mode-specific outcomes in patients with chronic heart failure. Heart 2018;104:993-8.

19. Albert NM. A systematic review of transitional-care strategies to reduce rehospitalization in patients with heart failure. Heart Lung 2016;45:100-13.

20. Horwitz L, Lin Z, Grady J, et al. Hospital-Wide (All-Condition) 30 day Risk-Standardized readmission measure draft measure methodology report Submitted, 2011.

21. Mirkin KA, Enomoto LM, Caputo GM, et al. Risk factors for 30-day readmission in patients with congestive heart failure. Heart Lung 2017;46:357-62.

22. Busby J, Purdy S, Hollingworth W. A systematic review of the magnitude and cause of geographic variation in unplanned hospital admission rates and length of stay for ambulatory care sensitive conditions. BMC Health Serv Res 2015;15:324.

23. Wick J, Hemmelgarn B, Manns B, et al. Comparison of methods to define high use of inpatient services using population-based data. $J$ Hosp Med 2017;12:596-602.

24. Kim H, Helmer DA, Zhao Z, et al. Potentially preventable hospitalizations among older adults with diabetes. Am J Manag Care 2011;17:419-26.

25. Canadian Institute for Health Information. High Users of Hospital Beds : Methodology - Appendix, 2018. Available: http:// indicatorlibrary.cihi.ca/download/attachments/8028191/High\% 20Users\%20of\%20Hospital\%20Beds $\% 20 \%$ E2\%80\%93\% 20Appendix. pdf?version $=1$ \&modificationDate $=1525277931000 \& a p i=$ v2 [Accessed 21 Aug 2018].

26. Ronksley PE, Hemmelgarn BR, Manns BJ, et al. Potentially preventable hospitalization among patients with $C K D$ and high inpatient use. Clin J Am Soc Nephrol 2016;11:2022-31.

27. Matesanz-Fernández M, Monte-Secades R, ÍñiguezVázquez I, et al. Characteristics and temporal pattern of the readmissions of patients with multiple hospital admissions in the medical departments of a general Hospital. Eur J Intern Med 2015;26:776-81.

28. Etxeberria-Lekuona D, Casas Fernández de Tejerina JM, Méndez López I, et al. Multiingreso en El Servicio de medicina interna de un Hospital terciario. Revista Clínica Española 2015;215:9-17.

29. Benjamin SM, Wang J, Geiss LS, et al. The impact of repeat hospitalizations on hospitalization rates for selected conditions among adults with and without diabetes, 12 us states, 2011. Prev Chronic Dis 2015;12:150274.

30. Freedland KE, Carney RM, Rich MW, et al. Depression and multiple rehospitalizations in patients with heart failure. Clin Cardiol 2016;39:257-62.

31. Goldfield NI, McCullough EC, Hughes JS, et al. Identifying potentially preventable readmissions. Health Care Financ Rev 2008;30:75-91.

32. Canadian Institute for Health Information. Indicator library: general methodology notes - clinical indicators, 2018. Available: http:// 
indicatorlibrary.cihi.ca/download/attachments/1114124/General Methodology Notes.pdf [Accessed 21 Aug 2018].

33. Ponikowski P, Voors AA, Anker SD, et al. Esc guidelines for the diagnosis andtreatment of acute and chronic heart failure. Eur Heart J 2016;2016:2129-200.

34. Ross JS, Mulvey GK, Stauffer B, et al. Statistical models and patient predictors of readmission for heart failure: a systematic review. Arch Intern Med 2008;168:1371-86.

35. Sawano M, Shiraishi Y, Kohsaka S, et al. Performance of the MAGGIC heart failure risk score and its modification with the addition of discharge natriuretic peptides. ESC Heart Failure 2018:5:610-9.

36. Pocock SJ, Ariti CA, McMurray JJV, et al. Predicting survival in heart failure: a risk score based on 39372 patients from 30 studies. Eur Heart J 2013;34:1404-13.

37. Quan H, Sundararajan V, Halfon P, et al. Coding algorithms for defining comorbidities in ICD-9-CM and ICD-10 administrative data. Med Care 2005;43:1130-9.

38. Brown D, Allik M, Dundas R. Carstairs Scores for Scottish Postcode Sectors, Datazones \&Output Areas from the 2011 Census. Glasgow: University of Glasgow, 2014. Available: http://eprints.gla.ac.uk/ 99555/1/99555.pdf

39. Portugal S. Statistical data, 2018. Available: https://www.ine.pt/ xportal/xmain?xpid=INE\&xpgid=ine_base_dados\&contexto=bd\& $\mathrm{selTab}=\mathrm{tab} 2$

40. Eurostat. Revision of the European Standard Population: Report of Eurostat's tak force, 2013.

41. Rabe-Hesketh S, Skrondal A. Multilevel and longitudinal models: when and why? in: multilevel and longitudinal modeling using Stata. Vol I. Stata Press, 2012.

42. Peugh JL. A practical guide to multilevel modeling. J Sch Psychol 2010;48:85-112.

43. Landerman LR, Mustillo SA, Land KC. Modeling repeated measures of dichotomous data: testing whether the within-person trajectory of change varies across levels of between-person factors. Soc Sci Res 2011;40:1456-64.
44. Philbin EF, DiSalvo TG. Prediction of hospital readmission for heart failure: development of a simple risk score based on administrative data. J Am Coll Cardiol 1999;33:1560-6.

45. Robertson J, McElduff $P$, Pearson S-A, et al. The health services burden of heart failure: an analysis using linked population health data-sets. BMC Health Serv Res 2012;12.

46. Al-Omary MS, Khan AA, Davies AJ, et al. Outcomes following hear failure hospitalization in a regional Australian setting between 2005 and 2014. ESC Heart Failure 2018;5:271-8.

47. Dharmarajan K, Hsieh AF, Kulkarni VT, et al. Trajectories of risk after hospitalization for heart failure, acute myocardial infarction, or pneumonia: retrospective cohort study. BMJ 2015;350.

48. Agler R, De Boeck P, De BP. On the interpretation and use of mediation: multiple perspectives on mediation analysis. Front Psychol 2017;8:1-11.

49. Gheorghiade $\mathrm{M}$, Vaduganathan $\mathrm{M}$, Fonarow GC, et al. Rehospitalization for heart failure: problems and perspectives. J Am Coll Cardiol 2013;61:391-403.

50. McCormick N, Lacaille D, Bhole V, et al. Validity of heart failure diagnoses in administrative databases: a systematic review and meta-analysis. PLoS One 2014;9:e104519.

51. Setoguchi S, Stevenson LW. Hospitalizations in patients with heart failure: who and why. J Am Coll Cardiol 2009;54:1703-5.

52. Zsilinszka R, Mentz RJ, DeVore AD, et al. Acute heart failure: alternatives to hospitalization. JACC Hear Fail 2017;5:329-36.

53. Wever-Pinzon O, Drakos SG, Fang JC. Team-Based care for advanced heart failure. Heart Fail Clin 2015;11:467-77.

54. Hebert K, Dias A, Franco E, et al. Open access to an outpatient intravenous diuresis program in a systolic heart failure disease management program. Congest Hear Fail 2011;17:309-13.

55. Lazkani M, Ota KS. The role of outpatient intravenous diuretic therapy in a transitional care program for patients with heart failure: a case series. J Clin Med Res 2012;4:434-8.

56. Dunlay SM, Redfield MM, Weston SA, et al. Hospitalizations after heart failure diagnosis a community perspective. J Am Coll Cardiol 2009;54:1695-702. 